\title{
LOS FANS DE ÚLTIMO MINUTO DE JUEGO DE TRONOS
}

\section{LAST-MINUTE FANS OF GAME OF THRONES}

\author{
José Alejandro Leyva Alvarado
}

Universidad Juárez Autónoma de Tabasco, México

(iD) https://orcid.org/0000-0003-3245-2063

\section{Elia Margarita Cornelio-Marí}

Universidad Juárez Autónoma de Tabasco, México

(iD) https://orcid.org/0000-0001-5495-1870

Autora para correspondencia: Elia Margarita Cornelio-Marí, email: elia.cornelio@ujat.mx

\section{Resumen}

Se analizan las prácticas de espectadores mexicanos que se convirtieron en fans de Juego de Tronos (HBO, 2011 2019) cuando se acercaba a su conclusión. Esta serie es un ejemplo de televisión compleja que promueve un fuerte involucramiento emocional. Así mismo, es contenido preciado de distribución global que las audiencias buscan y desean ver completo. Se aplicaron 10 entrevistas semi-estructuradas que incluyeron tres dimensiones: (a) historia personal con la serie, (b) ver la serie como maratón (binge-watching), y (c) ser fan. Los participantes reportaron que la presión para iniciar a ver la serie había provenido de sus amigos, profesores y familiares, o de las publicaciones que habian visto en sitios de redes sociales. Una vez enganchados en Juego de Tronos, los espectadores tomaron parte en las prácticas típicas de los fans, como hacer fanart, cosplay y comprar mercancía, sin importar el momento en que habían iniciado a ver la serie. Se confirma que el nuevo contexto televisivo, caracterizado por la amplia disponibilidad de contenidos en servicios de distribución digital, permite a los espectadores ponerse al día a través de maratones para incorporarse rápidamente a fenómenos televisivos en boga.

Palabras clave: distribución digital, consumo televisivo, fans, maratones televisivos, Juego de Tronos.

\begin{abstract}
We analyzed the practices of Mexican viewers that became fans of Game of Thrones (HBO, 2011-2019) when it was approaching its finale. This series is an example of complex television that creates strong emotional engagement. At the same time, it is prized content of global reach that audiences search and want to watch in full. We applied 10 semi-structured interviews that included three dimensions: (a) personal history with the series, $(b)$ watching as a marathon (binge-watching), and (c) being a fan. The participants reported that the pressure to start watching came from friends, professors and family members, or from the posts they had seen on social network
\end{abstract}

Global Media Journal México, 18(34), 185-208, enero - junio 2021. 
sites. Once they were hooked in Game of Thrones, viewers took part in typical fan practices, like fanart, cosplay and buying merchandise, regardless of the moment they had started watching. We confirmed that the new context of television, characterized by the large availability of content through digital delivery services, allows viewers to catch-up through marathons to quickly become part of television trends.

Keywords: digital delivery, television viewing, fandom, binge-watching, Game of Thrones.

Recibido: 12/04/2021

Aceptado: 07/06/2021

\section{Introducción}

En los últimos años la distribución de contenidos televisivos ha cambiado notablemente. Se ha pasado de la predominancia de la televisión tradicional abierta y de paga -, a la presencia cada vez más amplia de los sistemas de distribución digital en línea también conocidos como streaming, Video-onDemand (VOD) o televisión por Internet. Como lo ha notado Amanda Lotz $(2014,2017)$ en el caso de los Estados Unidos, esta transición ha afectado todos los ámbitos del campo televisivo, incluyendo el financiamiento, la producción, la distribución, la promoción y el consumo.

La distribución digital hoy día promete a los televidentes el acceso a los contenidos según tres máximas: lo que quieran ver, cuando quieran verlo y donde quieran verlo (Barker y Wiatrowski, 2017; Tryon, 2013). Esta promesa está sujeta a limitantes de infraestructura y de costo, pero es preciso notar que la distribución digital también tiene lugar a través de plataformas ilegales o descargas, contribuyendo a crear una oferta sin precedentes de los contenidos más populares, aún entre sectores de la población de escaso poder adquisitivo o que viven bajo regímenes que restringen la difusión (Pertierra, 2012).

Como consecuencia, se están consolidando nuevas prácticas alrededor del medio televisivo, acordes a las facilidades de acceso. Este fenómeno se aborda a través de un estudio de recepción con audiencias mexicanas de la serie de fantasía Juego de Tronos (2011-2019), uno de los títulos más exitosos de los últimos años.

La noción de práctica que se utiliza en este trabajo tiene afinidad con el concepto propuesto por Reckwitz (2002), quien la plantea como un comportamiento rutinario en el que se interconectan: a) actividades realizadas con el cuerpo, b) actividades mentales, c) uso de objetos y d) un conocimiento de base (significados, saber práctico, emociones y motivación). Por tanto, se busca indagar sobre las nuevas rutinas que algunos espectadores están desarrollando alrededor de ciertos contenidos televisivos, las cuales no se circunscriben a mirar el programa sino que, como se verá, implican también participar en actividades creativas, compartir conocimientos y poner en juego las emociones. 
De manera específica, el objetivo es reflexionar con base en datos empíricos sobre cómo un segmento de la audiencia utilizó las nuevas condiciones de acceso para acercarse a Juego de Tronos durante las últimas dos temporadas del programa, apenas a tiempo para experimentar el final de la narrativa, con todo lo que este trajo de discusión pública y de involucramiento emotivo.

Este tipo de prácticas, en las que algunos espectadores se convierten en fans de los programas del momento debido a la presión de sus redes sociales, no son en absoluto privativas de la serie caso de estudio. En consecuencia, se justifica examinarlas porque ilustran procesos de concentración de las audiencias en un momento en que éstas se dispersan ante la creciente oferta de contenidos.

\section{Marco teórico}

Entender a plenitud el fenómeno planteado requiere comprender las características narrativas de Juego de Tronos (que la hacen crear un fuerte apego emocional entre los fans), así como las particularidades de su distribución (que le permitieron tener un alcance global).

Juego de Tronos, en inglés Game of Thrones, es una producción de la cadena televisiva HBO. La trama, ubicada en un mundo medieval imaginario en el que grandes casas nobiliarias luchan por el poder, se basa en las primeras cinco novelas de la saga literaria de George R. R. Martin titulada “Canción de hielo y fuego". La serie televisiva se comenzó a transmitir en 2011 y estuvo al aire hasta mediados de 2019, comprendiendo un total de 73 episodios de aproximadamente una hora de duración cada uno. A lo largo de su transmisión, Juego de Tronos ganó numerosos premios y es considerado por la crítica especializada como uno de los mejores programas de televisión de los últimos años.

Existen rasgos textuales en Juego de Tronos que la ubican en la categoría de televisión más innovadora de la época actual y que explican en parte su popularidad. La serie es un ejemplo de televisión compleja (Mittell, 2015), la cual se define como un nuevo paradigma de narración televisiva caracterizado por un grado elevado de reflexividad, que demanda mayor involucramiento de los espectadores:

Un nuevo paradigma de narración televisiva ha surgido en las últimas dos décadas, redefiniendo el límite entre las formas episódicas y seriales, con un mayor grado de autoconciencia en la mecánica de la narración y demandando un compromiso intensificado del espectador, centrado en los placeres diegéticos y la conciencia formal (posición en Kindle 1083-1085).

El modo narrativo de la televisión compleja, que habría surgido a finales de la década de 1990, redefine las fronteras entre lo episódico y lo serial. Esta característica queda ilustrada en proyectos innovadores para su época como Los Expedientes Secretos X (1993-2018), donde los capítulos 
episódicos de "el monstruo de la semana", se combinaban con un arco narrativo mucho más amplio y fuertemente seriado que se desarrollaba a través de varias temporadas.

Además, los títulos que se enmarcan en este modo narrativo utilizan dispositivos innovadores, como el relato a través de diversos puntos de vista, los saltos cronológicos, la construcción de personajes sofisticados - especialmente antihéroes -, y la integración de elementos que promueven su inserción en fenómenos transmedia. Algunos ejemplos destacados de televisión compleja serían Buffy la Cazavampiros (1997-2003), Los Soprano (1999-2007), Lost (2004-2010), Cómo Conocí a tu Madre (2005-2014), Mad Men (2007-2015) у Breaking Bad (2008-2013).

Sin duda, la complejidad de Juego de Tronos se nota a simple vista, ya que cuenta las historias entrelazadas de una veintena de personajes protagónicos, en múltiples escenarios y a lo largo de varios años, tejiendo un intrincado relato que solo los espectadores más atentos pueden seguir a la perfección. Al mismo tiempo, desde el inicio plantea enigmas narrativos que contribuyen a la riqueza y profundidad del universo de ficción que propone.

Mittell (2015) sostiene que la televisión compleja tiene como particularidad el llamar la atención sobre sus proezas narrativas mientras promueve el involucramiento emotivo. Es decir, las series como Juego de Tronos permiten asombrarse ante las hazañas histriónicas, de efectos especiales, musicales, de diseño de arte y de vestuario, así como

\footnotetext{
${ }^{1}$ Por ejemplo, en el episodio final de la serie el personaje
} Tyrion reflexiona “¿Qué une a las personas? ¿Ejércitos? del propio relato audiovisual. Igualmente, estas series propician un fuerte apego emocional con los personajes y los eventos. Como espectadores, estamos embebidos en la historia y maravillados por la manera en que ésta se nos presenta: "Vemos estas series no solo para dejarnos llevar por un mundo narrativo realista ... sino también para ver cómo funcionan los engranajes, maravillándonos de la habilidad necesaria para llevar a cabo tal pirotecnia narrativa." (Mittell, 2015, posición en Kindle 887889).

Por tanto, es común que este tipo de programas recompense a sus seguidores más fieles con momentos de autorreflexividad, con pistas escondidas e incluso con comentario metatextual, ${ }^{1}$ pues son precisamente esos detalles los que los fans más asiduos se deleitan en encontrar, mirando varias veces los episodios para después discutir sus hallazgos con otros seguidores. De tal forma, series como Juego de Tronos fomentan lo que Mittell (2015) ha llamado un fanatismo forense, que implica la actividad de escrutinio de los espectadores con el fin de vislumbrar los aspectos más mínimos de la trama y la producción de un programa para luego generar discusión colectiva tanto de modo presencial como virtual (en sitios de redes sociales como Facebook, Instagram o WhatsApp).

Aparte de las características narrativas de Juego de Tronos, que ya de por sí propician un mayor involucramiento de las audiencias, el programa se ha visto favorecido al ser lo que Lotz (2014) llama un contenido preciado, es decir: "programación que la el mundo más poderoso que una buena historia”. 
gente busca y desea específicamente" (posición en Kindle 429). Como especifica la autora, las audiencias actuales no se contentan con mirar lo que estén pasando en la televisión en ese momento, sino que buscan deliberadamente el contenido que desean.

Lo anterior se hace posible $-\mathrm{y}$ necesario porque las condiciones del entorno de la era de TV Plenty (Ellis, 2000), con su amplia oferta de contenidos en multitud de plataformas, contribuyen a crear un tipo de relación distinta entre el espectador y los programas televisivos. Se ha pasado de una escasez de contenido a una escasez del tiempo para verlo (Lotz, 2014), al grado tal que compañías como Netflix consideran que su competencia incluye actividades como jugar videojuegos, leer o incluso dormir (Hern, 2017).

Con tan grande oferta y tan poco tiempo, el proceso de selección de un programa no es tan lineal como solía ser en la época de la televisión abierta, cuando solo había un puñado de canales de dónde escoger.

En la actualidad un sector cada vez más amplio de espectadores, con acceso a Internet y competencias en el uso de las tecnologías, dispone de una gran oferta de contenido, mucho del cual está diseñado para verse como maratón (binge-watching); es decir, consumiendo varios capítulos a su propio ritmo (Merikivi et al., 2020).

Surge entonces la dificultad de escoger a qué nuevo programa dedicarle la atención por días, semanas o incluso meses enteros. Por eso los contenidos preciados adquieren relevancia, al ser aquellos títulos que, según crítica y público, merecen el esfuerzo de buscarse activamente para verse completos.

Como indica la propia Lotz (2014), la manera en que ciertos programas se discuten actualmente en la prensa y las redes sociales digitales, crea en los espectadores el deseo de mirarlos desde su primer capítulo:

La forma en que ciertos tipos de televisión han llegado a ser discutidos en la cultura ... ha inculcado nuevas expectativas en los espectadores. Después de leer interminablemente sobre Downton Abbey en artículos de periódicos y mensajes de Twitter, el espectador no iniciado no busca ver el último episodio, sino comenzar la historia desde su piloto. Incluso una transición de comportamiento tan pequeña es importante para imaginar un futuro televisivo muy diferente. (posición en Kindle 3016).

Los miembros de las audiencias reconocen cuando se trata de un programa televisivo que "hay que ver" porque las personas de su entorno hablan de él, se topan con memes y videos en sus sitios de redes sociales, llegan a escuchar que la crítica lo alaba o lo condena, e incluso que los medios tradicionales le dedican cobertura especial. Juego de Tronos sin duda fue un programa que concentró el discurso de fans y críticos por varios años, haciéndose particularmente notorio en los periodos de transmisión de nuevos capítulos. Por tanto, puede considerarse también un 
claro ejemplo de contenido preciado que los espectadores buscaban de manera activa.

En este aspecto, Juego de Tronos se benefició del nuevo escenario de la industria televisiva. Si miramos al contexto de su distribución, resulta claro que se trata de un programa que cabalga entre dos tiempos: el del broadcasting y el del streaming. A lo largo de su transmisión esta serie pasó, por un lado, de la distribución elitista de un canal de cable premium a la distribución digital y, por el otro, de la distribución diferida que privilegia el estreno en su país de origen a la distribución simultánea global.

Cuando Juego de Tronos inició transmisiones en 2011, para verla legalmente no había más opción que suscribirse a HBO como canal premium de cable o televisión por satélite. Cuando concluyó en 2019, el servicio de streaming HBO Go ya estaba disponible en muchas regiones. Por tanto, el acceso al programa de manera legal se había vuelto mucho más asequible, ya que el espectador podía pagar HBO directamente a través de una aplicación. De esta forma, la cadena eliminó intermediarios tanto en su mercado doméstico como otros países. Igualmente, la piratería se convirtió en la otra gran modalidad de distribución digital de la serie. Ya en 2013 Juego de Tronos era el programa más pirateado del mundo (Gilbert, 2013). No sorprende que esta situación se mantuviera ante la creciente popularidad de los sitios de streaming ilegales durante su transmisión.

Por otra parte, al principio de su transmisión la serie estaba sujeta a las reglas del sistema norteamericano de estrenos diferidos, con "ventanas" distintas para cada mercado, de modo tal que en algunos países los capítulos se estrenaban con semanas, e incluso meses, de retraso con respecto a los Estados Unidos. Sin embargo, cuando la serie alcanzó su temporada final ya contaba con lanzamiento simultáneo prácticamente en todo el mundo. Esta distribución más generalizada posicionó al programa en la oferta televisiva global, lo que repercutió en su presencia en el imaginario cultural y en la discusión pública del momento.

Como resultado de lo anterior, en sus ocho años de transmisión Juego de Tronos pasó del gusto de nicho de los seguidores de la fantasía al gusto de franjas más amplias de público. Siendo una narrativa transmedia (Jenkins, 2006; Scolari 2013), aún antes de llegar a la televisión ya se había expandido a los juegos de rol, las historietas y los juegos de video. Al principio sin duda resultó más atractiva para espectadores familiarizados con la saga de George R. R. Martin pero luego, con el programa de televisión como punto central, la popularidad de la historia se acrecentó. Así, Juego de Tronos rompería todos los récords de audiencia para episodios individuales en Estados Unidos, llegando a 19.3 millones de espectadores en la última temporada (Gallo, 2019), con un cálculo de 44.2 millones de espectadores por episodio a nivel global (Varon, 2019).

De esta forma, al ser una serie compleja, preciada y de amplia distribución, Juego de Tronos se cuenta como miembro indiscutible del reducido club de títulos de popularidad global que en cierto momento se convirtieron en casi obligados, como Breaking Bad (2008-2013), The Walking Dead (2010-2020), Black Mirror (2011 - presente), Vikings 
(2013 - presente), House of Cards (2013-2018), Stranger Things (2016 - presente), Dark (2017-2020) y The Crown (2016 - presente). En su momento todos ellos originaron una urgencia por ver, compartir opiniones y ser parte de la conversación. En este artículo se trata de dilucidar las prácticas que se alimentan de aquella urgencia, la cual se incrementa sobre todo cuando las series están a punto de concluir. Es un tipo de euforia en la que se combinan el discurso mediático y el discurso de las audiencias, creando presión entre los espectadores para sentirse parte del fenómeno mientras el programa todavía se encuentra en transmisión.

La relevancia de concentrarnos en quienes llamamos "fans de último minuto" surge de la necesidad de estudiar con mayor detenimiento a este segmento de consumidores mediáticos, que parecen encarnar las posibilidades de un entorno televisivo caracterizado por la abundancia de contenidos y la flexibilidad para acceder a ellos desde plataformas tanto legales como ilegales. No se sabe aún si sus prácticas podrían ser distintas de aquellas de los “fans tradicionales" y es esto precisamente lo que este proyecto buscó explorar, concentrándose en un caso de estudio excepcional, como lo fue Juego de Tronos.

\section{Método}

Este artículo presenta hallazgos obtenidos mediante la aplicación de entrevistas semi-estructuradas realizadas durante los meses de mayo a diciembre del 2019, al terminar la transmisión de la última temporada de Juego de Tronos. El objetivo de investigación era observar las prácticas de los espectadores que comenzaron a ver la serie entre la penúltima y la última temporadas. El estudio se concentra en las audiencias en México pero, tratándose de un país tan vasto, el trabajo de campo se vio restringido al ámbito geográfico de los investigadores en una región de provincia. El alcance del estudio es exploratorio y se limita a una muestra bastante reducida debido, en parte, a las dificultades de reclutamiento.

El requerimiento más importante para participar en el estudio era haber visto la mayor parte de la serie de forma continua; es decir, haber visto al menos seis de las ocho temporadas (equivalente a 60 capítulos) a su propio ritmo, fuera de los periodos de transmisión. Como resultado, se excluyó de las entrevistas a seguidores de larga data de la serie, que la hubieran comenzado a ver de 2011 a 2016. Esto permitió concentrarse en aquellos espectadores que decidieron iniciar a ver Juego de Tronos cuando ya estaba anunciada su conclusión.

El objetivo de los estudios cualitativos es profundizar, describir e interpretar, buscar lo distintivo más que generalizar hacia una población (Orozco y González, 2011). Por tanto, la muestra no tuvo la pretensión de ser representativa, sino que se buscó recopilar los puntos de vista de personas en contextos reales. En este sentido, el estudio se alinea con una perspectiva fenomenológica, pues busca "describir el significado para varios individuos de sus experiencias vividas de un concepto o un fenómeno" (Creswell, 2007, p. 57, énfasis en el original). 
La población de estudio fueron los estudiantes universitarios entre 18 y 25 años, uno de los grupos que más visiblemente se relaciona con el fenómeno del binge-watching (Vaterlaus et al., 2019). Se reclutó a 10 participantes usando la técnica de bola de nieve, obteniendo referencias de otros seguidores de Juego de Tronos, hasta ubicar a quienes tenían las características deseadas. Cuando se alcanzó la saturación teórica en las respuestas se cerró el reclutamiento. Este cierre también se debió a que, en los meses después de su conclusión, la serie paulatinamente perdió relevancia en el escenario mediático y fue más difícil encontrar a fans recién integrados al fenómeno. La muestra final se conformó por estudiantes de nivel licenciatura o recién egresados de una universidad pública de la provincia mexicana. Nueve de ellos cursaban en aquel momento las licenciaturas en idiomas, comunicación, odontología, rehabilitación física e ingeniería mecatrónica. Uno era recién egresado de la carrera en comunicación. Sus edades se ubicaban en el rango de los 19 a los 25 años. La lista de participantes se presenta en el apartado de resultados (Tabla 1), utilizando en todos los casos seudónimos para proteger su identidad.

La técnica de investigación seleccionada fue la entrevista semi-estructurada o semidirigida, en la que se plantean "temas y subtemas con preguntas amplias (no específicas), que permiten que el entrevistado pueda conectarse con el subtema abordado" (Orozco y González, 2011, p. 152). Como en todas la entrevistas, el objetivo es "captar los discursos, el lenguaje de los entrevistados [ya que se] intenta adentrarse en los motivos y representaciones de los individuos" (Orozco y González, 2011, p. 151). Con esto en mente, se elaboró una guía de preguntas que se concentraba en obtener información de tres dimensiones: (a) historia personal del entrevistado con Juego de Tronos (contexto en que miraba la serie usualmente, tipo de plataforma utilizada, compañía, hábitos y rituales que rodeaban la visión), (b) ver la serie como maratón (cantidad de capítulos vistos por sesión, duración total de la visión, percepciones respecto a esta modalidad de visión), y (c) ser fan (su propia percepción respecto a ser fan o no, las actividades que realizaba, su percepción de otros fans). El instrumento incluyó dieciséis preguntas abiertas, que podían aplicarse siguiendo un orden relativamente flexible. En mayo de 2019, se llevó a cabo una prueba piloto con un espectador de la serie, lo que permitió ajustar el orden de las preguntas y comprobar su validez.

Tras obtener el consentimiento informado de los participantes, se grabó el audio de todas las entrevistas y se transcribieron palabra por palabra. Posteriormente, las transcripciones se codificaron utilizando el software para análisis cualitativo ATLAS.ti. Cada uno de los autores realizó su propia codificación y luego se contrastaron las categorías emergentes de manera conjunta. Para el análisis se partió de las tres dimensiones incluidas en la guía de preguntas pero, conforme se avanzó con la codificación se identificaron cuestiones imprevistas, tal como las críticas que surgieron respecto al final de la serie y el impacto que esto pudiera tener en el interés de otros posibles seguidores. Los principales resultados del trabajo de campo se describen en el siguiente apartado.

Global Media Journal México, 18(34), 185-208, enero - junio 2021. 


\section{Resultados}

Las 10 entrevistas ofrecieron una gran riqueza de datos. Fragmentos del discurso de los participantes se presentan en forma de cita para ilustrar puntos relevantes de los hallazgos, los cuales se organizan con base a las tres dimensiones principales del análisis.

\section{a) Historia personal con la serie y condiciones de visión}

En esta primera parte nos enfocamos en ubicar las razones por la que los espectadores son atraídos hacia la serie, así como su experiencia personal con Juego de Tronos. En primer lugar, se encontró que varios de los nuevos fanáticos ya habían escuchado hablar de la serie anteriormente, pero se decidieron a verla justamente antes del estreno de la temporada final, cuando nuevamente comenzó a circular el discurso sobre el programa en su ambiente cotidiano y en las redes sociales digitales. Estos espectadores fueron influidos por la recurrente presencia del tema en los comentarios de amigos y familiares, como se ejemplifica a continuación:

La empecé a ver no hace mucho... antes de que saliera la última temporada, porque varios de mis amigos hablaban de ese tema y siempre que hablaban de eso, pues, sonaba interesante [Ernesto, estudiante de odontología, 19 años]. ${ }^{2}$

\footnotetext{
${ }^{2}$ Todos los pasajes de los participantes que se reportan en la sección de resultados son producto de comunicaciones personales con el primer autor,
}

También identificamos la importancia de las relaciones sentimentales como impulso para iniciar a ver Juego de Tronos. Por ejemplo, para Andrés y Gisela, ver la serie era un momento de convivencia propuesto por sus respectivas parejas pero, conforme se adentraron en la trama, la serie fue adquiriendo un aprecio más personal para ellos. Esto es notorio en sus comentarios:

Me daba pereza verla. Fue hasta que mi exnovio estuvo muy insistente conmigo, de que viera la serie, porque él es fanático ... insistió tanto que me terminó convenciendo [Andrés, egresado de comunicación, 23 años].

Empecé a salir con alguien y a esa persona le gustaba Game of Thrones, y estaba sorprendido de que yo no supiera qué era eso y ya fue que me la puso. ... Nunca como que me di el tiempo de saber qué era realmente, y ya como la pusieron, pues dije: "Ah, bueno" [Gisela, estudiante de comunicación, 25 años].

Un hallazgo interesante fue el rol de los profesores que comentaban la serie en sus clases, influyendo para que sus alumnos se animaran a verla. Este es el caso de Mauricio y Alberto, quienes al escuchar a profesores universitarios hablar sobre el fenómeno de Juego de Tronos se interesaron de inmediato, a

realizadas de mayo de diciembre de 2019. En todos los casos se indica el seudónimo, la ocupación y la edad. 
pesar de que ya anteriormente sus compañeros les habían recomendado la serie:

Pues fue a principios de semestre cuando un profe nos daba clases. Vi que varios de mi salón ya habian visto la serie y dicen "no, está buenísima", pero el profe trataba de conseguir lo que era la séptima temporada y dije ... “oras, está muy comentada la serie!" Y ya fue que desde ahi [que] yo dije "pues vamos a comenzar a verla" [Mauricio, estudiante de mecatrónica, 20 años].

Además de la convivencia en la vida cotidiana con personas que seguían y recomendaban la serie, los entrevistados también mencionaron los sitios de redes sociales digitales. Cuando se les preguntó sobre los motivos que les impulsaron a verla, algunos mencionaron escenas que circulaban en Facebook, lo que influyó en su decisión para adentrarse en ese universo narrativo:

En marzo [de 2019] creo que fue, que salió el capítulo donde un personaje quema toda una ciudad. Eso me llamó la atención, como lo quemó con un dragón, y empecé a ver la escena en Facebook y me llamó la atención, y fue que la empecé a ver [la serie] [Alicia, estudiante de idiomas, 23 años].

Algunos de los entrevistados iniciaron a ver la serie simplemente porque deseaban comenzar a ver algo nuevo y la encontraron en la oferta de su plataforma digital ilegal. Para Lázaro, Juego de Tronos ya encajaba con sus gustos, mientras que Yessenia fue persuadida por el póster que aparecía en la página donde estaba buscando algo más que ver:

A mí me gustaba mucho "El señor de los anillos", y ya las había visto. Aún tenía como esa sensación de "quiero ver algo de fantasía medieval", así que me puse a ver la serie como en 2017 y como sabía que decían que era muy, muy, buena pues... [me] la puse, a ver [Lázaro, estudiante de idiomas, 19 años].

Estaba en esta página "Mira de todo" y estaba yo buscando una serie, porque acababa yo de terminar una. Entonces dije: “Ay, pues a ver” y vi y me llamó la atención, y como vi que en la portada tenían una corona y estaban en un trono dije: "Ay, pues la voy a ver" [Yessenia, estudiante de idiomas, 23 años].

Después de analizar cuáles fueron los detonantes para que nuevos fans se sumaran a la fiebre de Juego de Tronos, indagamos cuáles fueron las plataformas que usaron. Se reportaron tres formas en la que se veían los capítulos: 1) por medio de archivos descargados en un disco duro o memoria USB, 2) páginas ilegales en línea y 3) HBO por cable/satélite o mediante la aplicación HBO Go. En coincidencia con las observaciones de otros autores (Duarte Hueros et al., 2016) la piratería en streaming es algo común entre los estudiantes universitarios 
entrevistados, ya que 9 de los 10 vieron la mayor parte de la serie utilizando páginas ilegales (Tabla 1). Solamente hubo una excepción, Patricia, quien encontró la escena en Facebook y luego vio toda la serie a través de la cuenta de HBO Go que le compartió una amiga, quien ya era fan.

Es que una amiga tiene el HBO. Me dijo que sí la veía con ella desde el principio otra vez, para ya poder ver la última temporada y pues eso fue lo que hice, verla con ella [Patricia, estudiante de idiomas, 20 años].

Debido a que la serie llevaba varios años de transmisión, no es de sorprender que dentro de la comunidad de fans circulara material descargado y transferido a través de memorias USB. Dos de los entrevistados tuvieron la disponibilidad de la serie completa gracias a la cercanía con fans más antiguos que disponían de los capítulos en almacenamiento digital.

Yo la vi por Internet, por una página que se llama "Mira de todo", que es HD y ahi están todas las temporadas. ... luego, bueno, creo que yo iba a la mitad de las temporadas y un amigo me pasó en una memoria todas las temporadas o los capítulos y ya las vi en mi tele, pero pues igual eran de Internet, descargados de Internet [Yessenia, estudiante de idiomas, 23 años].
El comentario anterior ilustra cómo algunos de los entrevistados utilizaron una combinación de plataformas, en las que las páginas de streaming piratas fueron el medio preferido. Entre los términos que más se repiten en los comentarios en este rubro estuvieron: "encontré en Internet", "se me facilitó" y "gratis", haciendo alusión a la predisposición entre este grupo al consumo de piratería, antes que al uso de plataformas oficiales. Sin embargo, también se encontraron casos en los que los fans comenzaron a ver la serie en páginas piratas, pero la última temporada la vieron por canales legales:

No, no, no te voy a mentir, no contraté $\mathrm{HBO}$ hasta la última temporada, sino [que] las vi en una página. Las vi, como están en stream todas las temporadas. Entonces para mí era sencillo nada más buscar la temporada y ya básicamente la página ya me los tenía ordenaditos por capítulo y toda la cosa. Y ya nomás era cuestión de seguir, y seguir, y seguir viendo [Andrés, egresado de comunicación, 23 años].

O sea, todos [mis primos] terminamos la serie, nos pusimos al día y ya cuando salió la nueva temporada fue que lo vimos en HBO, ya así como tal, capítulo por capítulo, cada domingo [Yessenia, estudiante de idiomas, 23 años].

La segunda gran dimensión de análisis fue la práctica de ver la serie en la modalidad de maratón, también conocido como atracón televisivo o binge-watching. 


\section{b) Ver Juego de Tronos como maratón}

La definición de binge-watching aún está en discusión por parte de los expertos, pero se acepta generalmente que es la visión de más de un episodio de la misma serie en una sola sentada, enfatizando la capacidad que tiene el espectador para controlar el tiempo y ritmo del consumo (Merikivi et al., 2020). Es decir, los dos factores centrales para identificar el binge-watching serían la autonomía del espectador y la continuidad. Otros requisitos serían que el contenido se vea en una plataforma distinta a la televisión tradicional y que las interrupciones se deban a factores de la vida cotidiana más que a horarios o pausas establecidas por un transmisor (Jenner, 2020). Como resultado, en esta modalidad se eliminan las esperas entre episodios y temporadas, con lo que se establece un modo de visión mucho más personalizado de los contenidos, los cuales generalmente son programas dramáticos fuertemente seriados (Rubenking et al., 2018).

En lo que respecta a la visión de Juego de Tronos, los entrevistados se interesaron en la serie meses previos a la emisión de la temporada final y unos pocos iniciaron a verla apenas días antes del estreno de la octava temporada, cuando se despertó su interés de formar parte del fenómeno. La mayoría vio todos los capítulos disponibles en maratones, a pesar de que las ocho temporadas son equivalentes a casi 70 horas de relato. La Tabla 1 reporta el momento en que los entrevistados iniciaron a ver la serie, el tiempo que tardaron y la cantidad de capítulos que vieron por día o semana.
De acuerdo con la información resumida en la tabla, apenas un par de los entrevistados inició a ver la serie durante la séptima temporada, mientras que la gran mayoría se integró a la visión en la pausa de 20 meses que hubo durante la séptima y la octava temporadas, de agosto 2017 a abril 2019. Solo uno de los entrevistados empezó a verla cuando la octava temporada ya estaba iniciada. Este patrón parece indicar que la larga pausa de transmisión decretada por $\mathrm{HBO}$, respaldada por la presencia de la serie en otras plataformas y medios, funcionó como un periodo en el que adquirió una gran cantidad de seguidores adicionales, quienes estuvieron dispuestos a ver las siete temporadas existentes de corrido, para luego unirse a la visión simultánea de los últimos capítulos.

La Tabla 1 muestra también que hubo diferentes ritmos de visión, ya que algunos participantes, aún teniendo todos los capítulos disponibles, se dieron un tiempo para verlos con calma. Este es el caso de Yessenia, Gisela y Ernesto. Yessenia mencionó que ella estaba interesada en ver la serie, pero tenía otros compromisos escolares que no le permitieron hacer maratón. Por su parte, Gisela comentó que como solamente la veía cuando estaba con su novio, tenía que esperar para ver los capítulos con él. El caso de Ernesto resulta interesante, porque decidió verla poco a poco al principio, ya que solo tenía curiosidad por saber a qué se debía tanto interés de la gente que le rodeaba:

Me llevé como la mitad del año, porque no la veía muy seguido. Haz de cuenta veía yo cuatro capítulos hoy y ya seguía yo como

Global Media Journal México, 18(34), 185-208, enero - junio 2021. 
dentro de dos semanas, tres semanas, porque, pues, al principio no está muy, muy interesante; no me llamaba mucho la atención [Ernesto, estudiante de odontología, 19 años].

Ernesto, quien veía la serie sobre todo para saber de qué hablaban sus amigos, apuntó durante la entrevista: “Antes no me parecía muy interesante, ahora ya que, como que... una opresión social [risa nerviosa] de que todos hablaban de eso y dije: 'bueno, está bien'. Me intrigó mucho.” Esta fuerte presión social a la que hace referencia, también lo habría llevado a acelerar la visión cuando llegó el final de la serie, "saltándose" temporadas para ver el desenlace, aunque luego tuviera que retomar los capítulos faltantes.

Todos los demás participantes, vieron la serie en periodos de entre tres semanas a dos meses, con excepción de Alicia, que la vio en tan solo una semana. Cabe señalar que ella se animó a ver la serie justo al final, ya que inició el domingo antes de que se emitiera el capítulo final. Reportó que miraba los episodios por la noche, a veces dejando de dormir:

A veces, te digo, me echaba, ¿diez?, que duran como 45 minutos. $O$ a veces nada más veía cuatro o cinco, dependiendo el sueño que tuviera y a qué hora lo había empezado a ver [Alicia, estudiante de idiomas, 23 años].
Seis de los 10 entrevistados experimentaron la serie viendo un promedio de dos a cuatro capítulos diarios, lo que implica una inversión de entre dos y cuatro horas al día. Este tipo de visión va de acuerdo con el perfil de los estudiantes universitarios, quienes tienen tiempo libre y periodos de vacaciones prolongados, además de estar familiarizados con la práctica del binge-watching (Rubenking et al., 2018).

Se detectó que los entrevistados habían tenido diferentes experiencias al ver Juego de Tronos como maratón. Estas fueron coincidentes en algunos casos, como en la percepción de que este modo de visión les permitía tener autonomía para elegir la cantidad de capítulos. Esta observación fue compartida por todos los participantes del estudio, ya que cada uno vio la serie a su propio ritmo, dependiendo de su disponibilidad. El siguiente comentario ilustra este punto:

Sí, porque, o sea, si yo quería me iba a dormir y le ponía pausa y me dormía. Y si no, pues bueno, seguía y veía todos los capítulos que quisiera sin esperar una semana o un mes ... sin comerciales, sin el doblaje, porque luego el doblaje igual es horrible [Alicia, estudiante de idiomas, 23 años].

Alicia también menciona otros aspectos que las audiencias, en la era de la distribución digital, han aprendido a esperar en sus prácticas de visión televisiva: la ausencia de pausas comerciales y la disponibilidad de distintas versiones lingüísticas, permitiendo que el espectador pueda seleccionar aquella de su preferencia. 


\section{Tabla 1.}

Características de los entrevistados y condiciones de visión

\begin{tabular}{|c|c|c|c|c|c|c|}
\hline Participante & Edad & $\begin{array}{l}\text { Momento en que } \\
\text { inició a ver la } \\
\text { serie }\end{array}$ & $\begin{array}{c}\text { Tiempo que } \\
\text { tardó en ver la } \\
\text { serie }\end{array}$ & $\begin{array}{l}\text { Frecuencia de } \\
\text { visión }\end{array}$ & $\begin{array}{l}\text { Con quién vio } \\
\text { la serie }\end{array}$ & $\begin{array}{c}\text { Dónde vio la } \\
\text { serie }\end{array}$ \\
\hline Patricia & 20 & $\begin{array}{l}\text { Inicio de } 7 a . \\
\text { temporada }\end{array}$ & $1 \mathrm{mes}$ & $\begin{array}{l}\text { 3-4 capítulos al } \\
\text { día }\end{array}$ & Amiga & HBO Go \\
\hline Yessenia & 23 & $\begin{array}{c}\text { Inicio de } 7 \mathrm{a} . \\
\text { temporada }\end{array}$ & 6 meses & $\begin{array}{l}1 \text { capítulo a la } \\
\text { semana }\end{array}$ & Familia & $\begin{array}{c}\text { Sitio web } \\
\text { ilegal/descarga/ } \\
\text { HBO Go }\end{array}$ \\
\hline Mauricio & 20 & $\begin{array}{c}\text { Pausa entre } 7 \mathrm{a} . \mathrm{y} \\
\text { 8a. temporadas }\end{array}$ & 3 semanas & $\begin{array}{c}5 \text { capítulos al } \\
\text { día* }\end{array}$ & Solo & Sitio web ilegal \\
\hline Andrés & 23 & $\begin{array}{c}\text { Pausa entre } 7 \mathrm{a} . \mathrm{y} \\
\text { 8a. temporadas }\end{array}$ & $1 \mathrm{mes}$ & $\begin{array}{c}3 \text { capítulos al } \\
\text { día* }\end{array}$ & En pareja & $\begin{array}{c}\text { Sitio web } \\
\text { ilegal/HBO Go }\end{array}$ \\
\hline Jaime & 22 & $\begin{array}{c}\text { Pausa entre } 7 \mathrm{a} . \mathrm{y} \\
\text { 8a. temporadas }\end{array}$ & 1 mes y medio & $\begin{array}{c}2 \text { capítulos al } \\
\text { día* }\end{array}$ & Solo & $\begin{array}{c}\text { Sitio web } \\
\text { ilegal/descarga }\end{array}$ \\
\hline Lázaro & 19 & $\begin{array}{c}\text { Pausa entre } 7 \mathrm{a} . \mathrm{y} \\
\text { 8a. temporadas }\end{array}$ & $1 \mathrm{mes}$ & $\begin{array}{c}3 \text { capítulos al } \\
\text { día }\end{array}$ & Familia & Sitio web ilegal \\
\hline Gisela & 25 & $\begin{array}{c}\text { Pausa entre } 7 \mathrm{a} . \mathrm{y} \\
\text { 8a. temporadas }\end{array}$ & 1 año & $\begin{array}{l}1 \text { capítulo por } \\
\text { semana }\end{array}$ & En pareja & Sitio web ilegal \\
\hline Ernesto & 19 & $\begin{array}{c}\text { Pausa entre } 7 \mathrm{a} . \mathrm{y} \\
\text { 8a. temporadas }\end{array}$ & 6 meses & $\begin{array}{l}1 \text { capítulo por } \\
\text { semana }\end{array}$ & Solo & Sitio web ilegal \\
\hline Alberto & 20 & $\begin{array}{c}\text { Pausa entre } 7 \mathrm{a} . \mathrm{y} \\
\text { 8a. temporadas }\end{array}$ & 2 meses & $\begin{array}{c}2 \text { capítulos al } \\
\text { día }\end{array}$ & Solo & Sitio web ilegal \\
\hline Alicia & 23 & $\begin{array}{l}\text { Fin de } 8 \mathrm{a} \text {. } \\
\text { temporada }\end{array}$ & 1 semana & $\begin{array}{c}\text { Hasta } 10 \\
\text { capítulos al día }\end{array}$ & Sola & Sitio web ilegal \\
\hline
\end{tabular}

Global Media Journal México, 18(34), 185-208, enero - junio 2021. 
Por otra parte, los participantes también expresaron divergencias respecto a la experiencia de ver esta serie como maratón, especialmente en lo que se refiere a la comprensión de la trama. Aquí encontramos una contradicción entre los comentarios de diferentes entrevistados. Por un lado, hay quienes consideran que debido a la rapidez con la que vieron la serie en maratón no pudieron seguir el hilo argumental:

Mmm... ¡No!, siento que se me olvidó casi todo, lo hice solamente por ver. Tal vez si yo lo hubiera empezado desde el principio como que hubiera yo recordado que iba pasando, pero como todo fue muy rápido, como que no relacioné todo de la misma manera que otras personas [Ernesto, estudiante de odontología, 19 años].

Otros, por el contrario, manifestaron que ver la serie con capítulos dosificados dificulta la comprensión, ya que esperar una semana obliga a tener que repetir capítulos anteriores para recordar la trama:

Sí, fue algo como que te emociona, pero a la vez como que se te olvida qué pasó, y ver de nuevo el capítulo primero de la octava temporada y luego para estar pendiente del segundo [Mauricio, estudiante de mecatrónica, 20 años].

A pesar de que vieron la serie como maratón, los entrevistados reconocen que esperar un tiempo entre cada temporada trae beneficios, como el notar la evolución de los personajes:

Mmm, tiene lo positivo de que estaría viendo cómo evolucionan los personajes con los años y lo malo es que sólo podría ver un episodio por semana; me tendría que hacer esas pausas que hacen de un año para ver lo siguiente [Lázaro, estudiante de idiomas, 19 años].

De hecho, para algunos de los entrevistados que iniciaron a ver Juego de Tronos en la pausa durante las temporadas 7 y 8 , se presentó una dificultad al pasar de un modo de visión a otro. Es decir, para algunos ver la serie en maratón y la última temporada en vivo supuso una ruptura del control que sentían tener:

Pues sí, fue estresante porque digamos que me mataba la curiosidad [entre risas] y eso fue gracioso porque fue como que, es un sentimiento que no había sentido. Y, dirías tú, como lo vi en maratón, no estaba acostumbrada [risas] [Gisela, estudiante de comunicación, 25 años].

También en esta categoría surgieron reflexiones respecto al nivel de fanatismo que se crea al seguir la serie durante su transmisión en vivo, en comparación con verla como maratón. Yessenia y Patricia dijeron que entre más tiempo se esté siguiendo el contenido de una serie, mayor es el fanatismo que se crea en el espectador. Un ejemplo en el siguiente comentario: 
Eh, obviamente tener que verlo en maratón es una súper ventaja, porque pues ya no te tienes que quedar esperando, el problema es que te acabas rápido las temporadas y ya te quedas: "aaay, a esperar a que salga la otra”. Y acá no, acá verlos uno cada domingo, obviamente incrementaba el que ya estábamos toda la semana "ya falta un dia, faltan dos dias, faltan tres". Entonces, eso como que aumentaba el fanatismo por la serie porque nos dejaba: “¿y qué va a pasar y qué va a pasar?" [Yessenia, estudiante de idiomas, 23 años].

Esta opinión, que revela la relación entre el apasionamiento y la modalidad de visión, ${ }^{3}$ nos permite ligar con la tercera dimensión de análisis, que se refiere precisamente a los comentarios respecto al hecho de considerarse parte de la comunidad de fans de Juego de Tronos.

\section{c) Ser fan}

En esta última dimensión nos concentramos en identificar cuáles han sido las razones por las que estos espectadores, que se unieron al fenómeno

\footnotetext{
${ }^{3}$ Mirar los episodios cuando son estrenados permite a los espectadores ser parte de las discusiones en redes sociales digitales y con la propia comunidad. Esta posibilidad de crear tendencia es la que está también impulsando a nuevos servicios de Subscription Videoon-Demand (SVOD), como Disney+ y AppleTV, para regresar al paradigma de lanzar un episodio a la semana, oponiéndose al modelo de temporadas completas que Netflix ha impulsado desde 2013.

${ }^{4}$ Esta escala del 1 al 10 no tiene la intención de discriminar entre quienes son fans y quienes no lo son, ya que esta última es una cuestión muy compleja. Se
}

durante las últimas temporadas, se sienten o no fans de Juego de Tronos. Se les preguntó qué tan fans se consideraban de la serie, a su criterio qué los hacía fans, las actividades de fandom que realizaban, las reflexiones sobre el apasionamiento de los seguidores más antiguos y su perspectiva como recién llegados a Juego de Tronos.

Como una manera de graduar el apego que los participantes sentían hacia la serie, se les preguntó el "nivel de fan" en el que se colocarían a sí mismos, en una escala del 1 al $10 .{ }^{4}$ Esta es una autopercepción de los participantes, que indica cómo se ubican con respecto a otros fans que ellos conocen. Sus respuestas se muestran en la Figura 1. La gráfica también contiene el año en que cada entrevistado inició a ver la serie.

Resulta interesante que solo uno de los entrevistados no se consideró fan en absoluto. Ernesto, como ya hemos visto, había reconocido que él solamente quería ver la serie para entender de lo que platicaban sus amigos. Se le puede catalogar como alguien que se dejó llevar por la presión social pero no sentía una gran atracción personal por el programa, lo que también pudo haber interferido en su comprensión de la trama. Jaime se colocó en un

planteó a los participantes como una pregunta que les permitiera ubicarse a sí mismos con respecto a otros espectadores de la serie que ellos conocieran. Por lo tanto, se trata de una escala subjetiva que refleja su percepción. En la guía de preguntas esta cuestión venía expresada de la siguiente manera: “¿Qué tan fan te consideras de la serie?". Sin embargo, en la prueba piloto el participante encontró dificultades para responder a este cuestionamiento abierto, por lo que se decidió preguntar de manera complementaria a los participantes cómo se colocarían a sí mismos en una escala numérica. 
nivel intermedio, justificando que a pesar de estar interesado en comprar mercancía relacionada a la serie, no compraría artículos ostentosos, sino algo significativo, como la banda sonora.

La mayoría de los entrevistados se dio una calificación por encima de 8 , que es bastante alta. Durante la entrevista, cada uno de ellos justificó la razón por la que se colocaron en ese punto de la escala, resaltando que no se ponían una calificación mayor porque sabían que había otros fans haciendo más actividades que ellos. Lo que sigue es un listado de acciones que estos fans de último minuto mencionaron durante las entrevistas:

- Buscar información sobre la producción y el detrás de cámaras de la serie

- Ver entrevistas de los actores hablando sobre la serie

- Buscar contenido sobre la serie en redes sociales digitales (Facebook y YouTube)
- Compartir y reaccionar a imágenes o memes con otros fans

- Leer teorías

- Hacer cosplay

- Ver maratones de todas las temporadas

- Convencer a otros para realizar actividades relacionadas con la serie

- Integrar frases y términos propios de la serie (p. ej. "El invierno se acerca", "Valar Morghulis", "Drakaris") en el habla y en la convivencia cotidiana con otros seguidores

- Discutir con otros fans sobre inconformidades que tuvieran con la trama, o para exponer puntos de vista y teorías creadas por ellos mismos

- Tener la intención de comprar los libros de J.R.R. Martin o mercancía de la serie en un futuro.

\section{Figura 1.}

Qué tan fan se consideran los participantes

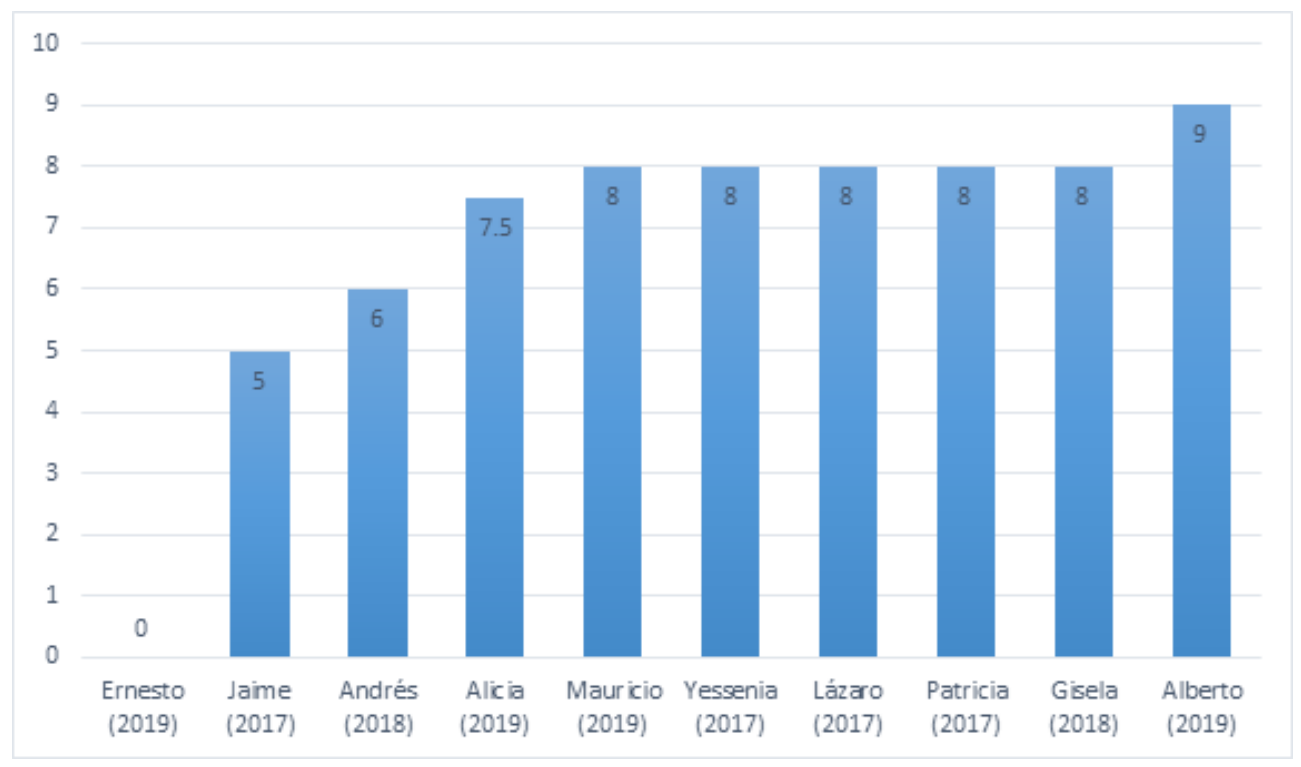

Global Media Journal México, 18(34), 185-208, enero - junio 2021. 
Lo anterior concuerda con las afirmaciones de Jenkins (1992, 2006), en el sentido de que los fans forman parte de culturas participativas, no solo dispuestas a consumir sino también a discutir y crear productos alrededor de los textos que les apasionan.

Hay que destacar que, a pesar de que los entrevistados se integraron al fenómeno Juego de Tronos al final de la serie, experimentaron la necesidad de involucrarse más allá de solo ver los capítulos. Entre las actividades más comunes que mencionaron estaban compartir memes con personas con las que tenían ese gusto en común, así como poner frases o imágenes en sus estados de redes sociales digitales. Lázaro, quien vino a la entrevista con una playera de Juego de Tronos, mencionó que a él le gustaría comprar más mercancía, pero como no tenía tanto dinero, no lo hacía. Gisela admitió entre risas que en una ocasión se vistió como algún personaje de la serie y se tomó fotos. De hecho, un par de entrevistados mencionaron el cosplay:

Una vez le corté el cabello a mi hermana como Ned Stark. La maquillé así porque pues ella tiene el cabello café. A mí me molestaban de que yo era Daenerys, pero me decian: "No, porque eres bien enojona, no puedes ser ella. Bueno, quizá sí porque estás loca”. Y empecé a, como a mi me gustaba, empecé a convencer, te digo, a mi primo y a mi novio de que se disfrazaran de Jon Snow. Entonces fue como mi aporte a la humanidad ... y ya mi primo se la pasa diciendo que él es Jon Snow, hasta la fecha. Igual dibujaba yo mucho los escudos [Yessenia, estudiante de idiomas, 23 años].
El extracto anterior muestra que estos fans sentían la necesidad de demostrar que pertenecen o son parte de una comunidad $\mathrm{y}$, a pesar de que los 10 entrevistados se integraron cerca del final de Juego de Tronos, realizaron varias de las actividades típicas de un fan.

Otro aspecto que interesaba mucho explorar en el proyecto eran las apreciaciones de los fans de último minuto con relación a las posible vivencias de fans más antiguos. Aquí resalta la apreciación de qué tan importante, o no, es haber llegado al universo de Juego de Tronos desde sus inicios. Se encontraron dos posturas:

\section{Sí es el mismo sentimiento, porque tanto} nuevos como antiguos fans ven la misma serie: Algunos de los entrevistados reflexionaron que la serie no necesita de un tiempo específico para ser disfrutada. Para algunos, el que haya espectadores que comenzaron a ver la serie desde años anteriores no los convierte en mejores fanáticos de aquellos que recién se enteraron de Juego de Tronos, argumentando que al tratarse de la misma serie, todo el que se envuelva en la trama deberá de tener el mismo apasionamiento, no importando el tiempo en que la vean. El siguiente comentario apoya esta idea:

Mmm, aunque la vi mucho después, aún así, vi lo mismo que otros vieron y vi los mismos personajes pasar por lo mismo y me dejó mucha intriga al igual que a los demás, así que me... sentí lo mismo que cualquier fan [Lázaro, estudiante de idiomas, 19 años]. 


\section{No es el mismo sentimiento porque los} fans más antiguos estuvieron expuestos a la serie por más tiempo: En contraparte, una porción de los entrevistados apoya la idea de que los espectadores más antiguos aprovecharon la emoción que rodeaba a la serie durante el tiempo que se mantuvo en transmisión, experimentando un apasionamiento generado tras años de seguimiento de la trama. Por ese motivo los nuevos adeptos de la serie tendrían menor apreciación. En los siguientes comentarios se puede notar esto:

Como que ya, igual, no sé, siento que está más familiarizado, por así decirlo. Y esperar todo eso como que, desde el 2011, esperar cada temporada a ver qué pasa ... como que se guarda más ese sentimiento de "¿qué va a pasar?". Y al final, pues sí como que lo ha de sentir más, no sé. Al menos yo lo vi como que todo de un jalón y fue como que muy rápido, pues, sentir todo eso [Jaime, estudiante de rehabilitación física, 22 años].

Eh, pues no como tal porque yo no tuve que esperar así, año con año a que se estrenaran las temporadas, y ... no pude como que tener esa colectividad de ver lo que todos los demás ponían cuando veían el episodio. Entonces creo que, pues la emoción de una persona que empezó a verla desde el 2011, pues creo que sí es un poco más fuerte que yo, que la vi así todas de una sola sentada [Patricia, estudiante de idiomas, 20 años].
El colofón del análisis en esta dimensión mostró que los entrevistados reconocieron que los nuevos espectadores que se interesen en la trama ahora que ya ha acabado la serie se encontrarán con dos situaciones:

a. Sí se podrá disfrutar de la serie, pero sin experimentar la interrogante que la rodeaba. Igual a la postura del punto anterior, una parte de los entrevistados reconocen que algo del valor que tiene la serie es todo el colectivo de fanáticos que la promueve, pero concluyen que aún así es una buena serie que se disfruta en maratón y sin esperas:

Pues, creo que no va a ser igual tanta emoción, porque no vivió como todo ese recorrido que una persona en el 2011 vio, o ¿no?, sintió como las condiciones que te daba el esperar cada domingo por la última temporada. Entonces creo que no, o sea, sí la van a disfrutar y sí va a ser algo padre para ellos, pero no va a ser el mismo sentido de comunidad, de que "iah, acabo de ver Game of Thrones y ya acabó!" [Patricia, estudiante de idiomas, 20 años].

Siento que quizá no sea la misma emoción de ver las dos últimas temporadas cada domingo. No creo que sea lo mismo, igual por la cantidad de spoilers que hay o, si no se hizo spoilers, pues porque ya es como que veo toda la serie en un año y iya, se acabó! No va a ser la misma emoción de cuando las teorías conspirativas que sacaban o de qué 
pensabas, sino aquí simplemente veo toda la serie, como una serie que ya está hecha, que ya esté terminada, y pues ya. No, siento que no va a ser el mismo sentimiento de fanatismo o adoración a los personajes, porque ya la ves completa, ya sabes que no pasa nada, porque ya sabes dónde acaba, entonces no hay nada que digas, "bueno, es que quién sabe el productor, quién sabe lo que digan" [Yessenia, estudiante de idiomas, 23 años].

\section{b. Los nuevos fans podrían estar} influenciados por los comentarios negativos de la última temporada. Entre los entrevistados hubo quien sugirió que la mala percepción pública de la última temporada puede provocar una predisposición a rechazar toda la serie:

Podría tener una primera impresión muy negativa porque, recordando, la primera temporada es pura introducción de personajes; la última temporada es un fiasco a grosso modo, a partir del criterio de muchas personas. Entonces todo esta bola de negatividad que levantó las personas que no les gustó la última temporada va a influenciar a los nuevos o los tentativos, la futura audiencia. Entonces yo creo que esto podría afectar su perspectiva de la serie porque van a decir "bueno, es que es una mala serie porque acaba mal". Porque ahorita lo que todo el mundo tiene en la cabeza es la última temporada, es lo que... todo el polvo que levantó. Eso podría sesgar mucho el criterio de una persona, que pues no sabe qué onda con Juego de Tronos en un principio [Alberto, estudiante de comunicación, 20 años].

\section{Conclusiones}

En el nuevo contexto de distribución digital de la televisión, por una parte, se facilita el acceso a muchos contenidos; por la otra, se desarrollan fenómenos ligados al alcance - e impacto cultural de algunos programas que por su distribución y popularidad adquieren un cariz global. Siguiendo a Lotz (2014), en este nuevo ambiente surgen contenidos preciados que las audiencias buscan y desean ver completos.

Podemos imaginar una especie de pinza: por un lado tenemos la creciente disponibilidad de títulos en plataformas legales e ilegales, por el otro tenemos la presión social, que se reproduce sobre todo en los sitios de redes sociales. Estos dos movimientos simultáneos crean las condiciones - el momentum para que ciertos programas televisivos se vuelvan casi obligados.

El trabajo de campo reveló que la presión social que experimentaron los entrevistados provino principalmente de dos fuentes complementarias: redes sociales tradicionales (amigos, familiares, profesores, otros fans), así como publicaciones y discusiones en sitios de redes sociales digitales como Facebook, YouTube e Instagram. En cuanto al primer aspecto, resalta el hecho de que Juego de 
Tronos se haya convertido en un elemento que refuerza la convivencia familiar o de pareja. Una de las entrevistadas, por ejemplo, explicaba cómo todos los jóvenes de su familia se reunían alrededor de la serie, haciendo cosplay e incluso vistiendo camisetas conmemorativas durante la transmisión.

En cuanto al segundo aspecto, ya está bien documentada la importancia de los foros y sitios de redes sociales digitales como lugar por excelencia donde los seguidores de las series comparten su pasión, discuten la teorías más recientes y dan a conocer sus opiniones (Jenkins, 2006; Mittell, 2015). En nuestro estudio se confirma que son también estos sitios donde los posibles interesados monitorean las tendencias, para enterarse de cuáles son los programas del momento de los que hablan sus conocidos y amigos. Pero este constante monitoreo también puede crear una cierta ansiedad, un miedo a perderse lo que está pasando (en inglés FoMo - fear of missing out), que deja a los individuos deseosos de pertenecer, de entender los chistes y de entrar en la conversación, aún si la serie no tiene un verdadero atractivo personal para ellos.

El FoMO aumenta las posibilidades de que una persona mire un drama seriado en el modo "mitad y mitad", es decir, la mitad en maratón y la otra mitad al tiempo del estreno (Conlin et al., 2016). Este es precisamente el modo en que la mayoría de nuestros participantes consumieron Juego de Tronos: la primera parte como maratón, tal vez por el deseo de ponerse al día sobre algo de lo que muchos estaban hablando; la segunda parte en la fecha de estreno, quizás para evitarse los famosos spoilers que arruinan la trama.
El escenario que resulta de este proyecto coincide fielmente con aquel descrito por Henry Jenkins en sus obras sobre las culturas participativas: "Textual poachers" (1992) y "Convergence culture" (2006). Estos espectadores de Juego de Tronos se conforman en comunidades creadas alrededor de un texto mediático, apropiándose de sus elementos narrativos y formales. Así, se visten como los personajes, los dibujan o modelan, visten ropa con logos e imágenes del programa e incluso citan frases en su habla cotidiana. Ser fan de Juego de Tronos se vuelve un rasgo de su personalidad que les permite ponerse en contacto con otros espectadores y sentirse parte de algo más grande.

Pero hay que recordar que "ser un fan es un estilo de vida" (Jenkins, 2006, p. 57) que se caracteriza por ser nómada. Es decir, esta pertenencia a la comunidad de seguidores de Juego de Tronos no es permanente, porque los fans obtienen placer al establecer lazos con una gran variedad de textos a la vez (Jenkins, 1992).

Por un tiempo, la serie actúa como un punto de atracción cultural que crea terreno en común para comunidades diversas y que se convierte en un activador para "la especulación, la elaboración y el desciframiento" (Jenkins, 2006, p. 95). En otras palabras, al acercarse a un fenómeno transmedia como Juego de Tronos, el espectador puede estar buscando una oportunidad para "explorar mundos complejos y comparar notas con otros" (Jenkins, 2006, p. 130), actividades que requieren empaparse de la trama porque hay que saber de qué están hablando los demás para poder opinar. Como la discusión, la especulación y los spoilers están ligados 
al momento en que se consume la serie, se refuerza la necesidad de hacer maratones para ponerse al día en poco tiempo.

Las series que se vuelven casi obligadas de ver por la presión social no son para nada un fenómeno nuevo. Siempre han existido los éxitos que tenían a todos pegados frente a la pantalla del televisor al mismo tiempo. Sin embargo, el nuevo escenario de distribución de los contenidos promueve prácticas que tienden hacia la visión individualizada y con ritmos diferentes para cada espectador, similar al consumo de libros o música (Lotz, 2017). La nueva configuración de accesibilidad permite ponerse al día en relativamente corto tiempo, ya que el binge-watching es una práctica aceptable (Steiner, 2017), que además es muy popular entre los jóvenes universitarios (Panda y Pandey, 2017; Rubenking et al., 2018).

Una vez enganchados, los fans recién llegados a un fenómeno televisivo se sienten parte de comunidades y están dispuestos a seguir artistas en las redes sociales digitales, buscar información sobre la producción, tomar parte en debates, comprar mercancía, aprender las canciones, crear artesanías, hacer largas filas para tomarse una foto en la réplica del Trono de Espadas, ir a restaurantes a ver los episodios de manera comunal, entre otras prácticas. Esto, a pesar de estar conscientes que el fenómeno al que se están integrando tiene ya una historia en la que otros fans participaron desde el inicio.

$\mathrm{El}$ argumento que hemos desarrollado hasta ahora es una reflexión sobre estos fans que, no por llegar en estadios avanzados de la narrativa, muestran menor grado de pasión. El caso de estudio permitió explorar las prácticas de las audiencias que se apropian de narrativas transmedia que son contenido preciado de carácter global y al mismo tiempo ejemplos de televisión compleja capaz de crear gran apego emotivo.

La principal aportación fue arrojar luz sobre un fenómeno de la cultura popular contemporánea, como son las prácticas de las audiencias en un nuevo contexto de distribución televisiva, cuyo perfil aún no termina por definirse de manera clara. Además, el estudio ha permitido obtener datos empíricos sobre el binge-watching, un fenómeno en boga que está atrayendo el interés de estudiosos en una gran variedad de disciplinas (Flayelle et al., 2020).

El proyecto tuvo como limitantes el quedarse en el nivel exploratorio, pues habría que ampliar la muestra de participantes para poder hablar de la prevalencia del fenómeno y conocer qué tan común es el arrastre de ciertos programas. Otra limitación es la rareza del caso de estudio, ya que series con el alcance de Juego de Tronos no son comunes. Finalmente, se debe reconocer que con un texto como éste se abren posibilidades de recepción muy diversas, pues las audiencias de distintos lugares del mundo necesariamente tendrán vivencias teñidas por su cultura local.

Para proyectos futuros queda pendiente profundizar en las motivaciones de aquellos televidentes que se involucran en series a punto de concluir. Dicha arista podría aportar a la comprensión de los procesos de agregación de los públicos, que van a contracorriente de la desagregación que está provocando el declive de la televisión abierta. 


\section{Referencias bibliográficas}

Barker, C. y Wiatrowski, M. (2017). The age of Netflix: critical essays on streaming media, digital delivery and instant access. McFarland \& Company.

Creswell, J. W. (2007). Qualitative inquiry \& research design: choosing among five approaches (2a ed.). Sage Publications.

Conlin, L., Billings, A. C. y Averset, L. (2016). Time-shifting vs. appointment viewing: the role of fear of missing out within TV consumption behaviors. Communication \& Society, 29(4), 151-164. https://doi.org/10.15581/003.29.4.151-164

Duarte Hueros, J., Duarte Hueros, A. y Ruano López, S. (2016). Las descargas de contenidos audiovisuales en Internet entre estudiantes universitarios. Comunicar: Revista científica iberoamericana de comunicación y educación, XXIV(48), 49-57. https://doi.org/10.3916/C48-2016-05

Ellis, J. (2000). Seeing things: television in the age of uncertainty. IB Tauris.

Flayelle, M., Maurage, P., Di Lorenzo, K. R., Vögele, C., Gainsbury, S. M. y Billieux, J. (2020). Binge-watching: what do we know so far? A first systematic review of the evidence. Current Addiction Reports, 7(1), 44-60. https://doi.org/10.1007/s40429-020-00299-8

Gallo, C. (22 de mayo de 2019). The best speech in the "Game Of Thrones" finale and why it matters to today's leaders. Forbes. https://bit.ly/3gfL4Lt

Gilbert, D. (31 de diciembre de 2013). The Hobbit and Game of Thrones top most pirated lists of 2013. International Business Times. https://bit.ly/3uxnPBu

Hern, A. (18 de abril de 2017). Netflix's biggest competitor? Sleep. The Guardian. https://bit.ly/3vywh4F

Jenkins, H. (1992). Textual poachers: Television fans and participatory culture. Routledge.

Jenkins, H. (2006). Convergence culture: where old and new media collide. New York University Press.

Jenner, M. (2020). Researching binge-watching. Critical Studies in Television, 15(3), $267-279$. https://doi.org/10.1177/1749602020935012

Lotz, A. D. (2014). The Television Will Be Revolutionized (2a ed.). New York University Press.

Lotz, A. D. (2017). Portals: a treatise on Internet-distributed television. University of Michigan Press.

Merikivi, J., Bragge, J., Scornavacca, E. y Verhagen, T. (2020). Binge-watching serialized video content: a transdisciplinary review. Television \& New Media, 21(7), 697-711. https://doi.org/10.1177/1527476419848578

Mittell, J. (2015). Complex TV: the poetics of contemporary television storytelling. New York University Press.

Orozco, G. y González, R. (2011). Una coartada metodológica: Abordajes cualitativos en la investigación en comunicación, medios y audiencias. Editorial Tintable.

Panda, S. y Pandey, S. C. (2017). Binge watching and college students: motivations and outcomes. Young Consumers, 18(4), 425-438. https://doi.org/10.1108/YC-07-2017-00707

Global Media Journal México, 18(34), 185-208, enero - junio 2021. 
Pertierra, A. C. (2012). If they show Prison Break in the United States on a Wednesday, by Thursday it is here: mobile media networks in Twenty-First-Century Cuba. Television \& New Media, 13(5), 399-414. https://doi.org/10.1177/1527476412443564

Reckwitz, A. (2002). Toward a theory of social practices: a development in culturalist theorizing. European Journal of Social Theory, 5(2), 243-263. https://doi.org/10.1177/13684310222225432

Rubenking, B., Bracken, C. C., Sandoval, J. y Rister, A. (2018). Defining new viewing behaviours: What makes and motivates TV binge-watching? International Journal of Digital Television, 9(1), 69-85. https://doi.org/10.1386/jdtv.9.1.69_1

Scolari, C. A. (2013). Narrativas transmedia: cuando todos los medios cuentan. Deusto.

Steiner, E. (2017). Binge-watching in practice: The rituals, motives and feelings of streaming video viewers. En C. Barker y M. Wiatrowski (Eds.), The age of netflix: critical essays on streaming media, digital delivery and instant access (pp. 141-161). McFarland \& Company.

Tryon, C. (2013). On-demand culture: Digital delivery and the future of movies. Rutgers University Press.

Varon, A. M. (20 de mayo de 2019). El episodio final de "Game of Thrones" rompe récord de audiencia en HBO. Agencia EFE. https://bit.ly/2SzHDqG

Vaterlaus, J. M., Spruance, L. A., Frantz, K. y Kruger, J. S. (2019). College student television binge watching: conceptualization, gratifications, and perceived consequences. Social Science Journal, 56(4), 470-479. https://doi.org/10.1016/j.soscij.2018.10.004

\section{Agradecimientos}

Los autores expresan su agradecimiento a los participantes en el estudio, a los revisores anónimos por sus atinadas recomendaciones, así como a Sadoc Contreras de la Cruz, Martha Elena Cuevas Gómez y Angélica María Fabila Echauri por sus generosos comentarios.

Global Media Journal México, 18(34), 185-208, enero - junio 2021. 